\title{
"INTERVAlo TerapêuTICo": UMA Resposta Para o Problema da Inserção Profissional das Pessoas Psicologicamente Frágeis?
}

\author{
"THERAPEUTICAL MI-TEMPS": A REPLY TO THE QUESTION \\ OF THE PROFESSIONAL INSERTION OF THE \\ PSYCHOLOGICALLY FRAGILE PERSONS?
}

Loïc Lerouge(*)

\section{RESUMO}

Analisa-se a proteção das pessoas psicologicamente frágeis no âmbito do direito sanitário do trabalho, na França, desde a introdução da noção de "saúde mental" no Código do Trabalho, em 2002. Examina-se o intervalo terapêutico, um dos dispositivos juridicos clássicos da prevenção, especialmente adequado à inserção profissional das pessoas psicologicamente frágeis. Demonstra-se que o intervalo terapêutico é um dispositivo de acompanhamento do trabalho que se pode apresentar como resposta às dificuldades de inserção das pessoas psicologicamente frágeis e, sobretudo, que esse dispositivo compreende os novos direitos, adequados ao tratamento da saúde mental no trabalho, dos trabalhadores psicologicamente frágeis, assegurando-Ihes um acompanhamento e um controle. Examinase, também, como aplicar o direito de aposentadoria do trabalhador que tem um motivo razoável para pensar que uma situação de trabalho apresenta um perigo grave e iminente para a sua vida ou a sua saúde, especialmente, para os trabalhadores psicologicamente frágeis.

\section{Descritores}

Direito Sanitário do Trabalho; Saúde Mental; Intervalo Terapêutico; Prevenção; Novos Direitos; Aposentadoria; Direito do Trabalho; Direito Sanitário.

(*) Doutor em direito - ATER na Faculdade de Direito de La Rochelle e Membro do laboratório Direito e Mudança Social CNRS UMR 6028 (Universidade de Nantes). Recebido: 19.4.04, Aprovado: 23.5 .04 . 


\section{ABSTRACT}

The protection of the psychologically fragile persons is analyzed within the scope of the Health and Labor Law, in France, since the introduction of the notion of "mental health" in the Labor Code, 2002. The author examines the "therapeutic interval", one of the classic legal devices of prevention, especially adjusted to the professional insertion of the psychologically fragile persons. He demonstrates that the "therapeutic interval" is a device of accompaniment of the work that can present itself as a reply to the difficulties of insertion of the psychologically fragile persons and, over all, that this device encompasses the new rights of the psychologically fragile persons, adequate to the treatment of the mental health in the work, assuring them an accompaniment and a control. It is examined, also, how to apply the right of retirement of the worker who has a reasonable reason to think that a work situation presents a serious and imminent danger for its life or its health, especially, for the psychologically fragile persons.

\section{Key words}

Health and Labor Law; Mental Health; Therapeutic Interval; Prevention; New Rights; Retirement; Labor Law; Health Law.

\section{INTRODUÇÃO}

O trabalho é uma das representações fundamentais da pessoa numa comunidade e participa, assim, em seu desenvolvimento individual e social. O trabalho é parte da dignidade da pessoa. O mundo do trabalho deve, portanto, ser acessivel a todos. Pessoas, cujo estado de saúde mental é frágil e inconstante, podem não ter ou perder o acesso a um emprego. Um violento choque emocional na vida pessoal ou profissional(1) pode alterar seriamente a saúde mental de certas pessoas. Uma vez fragilizada a saúde mental, sua inserção profissional torna-se problemática, tanto para o empregador quanto para o empregado.

Desde a introdução da noção de "saúde mental" no Código do Trabalho pela lei de modernização social de 17 de janeiro de $2002^{(2)}$, a proteção das pessoas psicologicamente frágeis torna-se cada vez mais uma pergunta que interessa ao direito sanitário do trabalho. Os trabalhadores psicologicamente frágeis ou vitimas de perturbações mentais estão em posição de fraqueza. Assim, devem ser protegidos e apoiados no ambiente de trabalho, pois seu estado de saúde mental pode depender diretamente desse apoio. É, por conseguinte, essencial abordar a questão das pes-

(1) Infelizmente os exemplos podem se multiplicar, tais como as violências conjugais, os adultos que sofreram violências durante sua infância, as agressões fisicas, a morte de um próximo, um acidente de automóvel, as tentativas de assédio sexual ou assédio moral ...

(2) Lei n. 2.002/73 de modernização social de 17 de janeiro de 2002, JORF de 18 janvier 2002 , p. 1008. 
soas psicologicamente frágeis no trabalho sob o ângulo da prevenção, complementando seu papel clássico com certos dispositivos juridicos, dos quais faz parte o intervalo terapêutico. Ele se coloca no centro do debate da inserção profissional das pessoas psicologicamente frágeis. Com efeito, quando do retorno na empresa, o intervalo terapêutico dá a possibilidade ao assalariado, vitima de acidente ou doença, de se beneficiar de uma retomada progressiva. Esse dispositivo pode ser aplicado quando o médico do trabalho considera que o trabalhador não está apto a retomar a sua atividade em tempo integral, mas que, entretanto, o seu estado de saúde é compativel com uma retomada em tempo parcial. Durante esse periodo, o assalariado percebe, além do seu salário, uma indenização diária vertida pela Caixa primária de seguro-saúde (Caisse primaire d'assurance maladie - CPAM) a fim de compensar a perda de salário que decorre da redução da sua atividade.

O principio do intervalo terapêutico baseia-se nas disposições do artigo L. 323-3 do Código da Seguridade Social. No caso de retomada do trabalho, a indenização diária pode ser mantida em parte pela Caixa, por uma duração determinada, se o retorno ao trabalho ou o trabalho efetuado pode favorecer a melhoria do estado de saúde do segurado ou se ele deve ser objeto de reeducação ou readaptação profissional para recuperar um emprego compativel com o seu estado de saúde. No entanto, o benefício deste dispositivo é possivel apenas após um exame de aptidão prévio à retomada do trabalho. Com efeito, em virtude do artigo R. 241-51 do Código do Trabalho, após ausências por doença profissional, acidente do trabalho (pelo menos 8 dias), doença ou acidente não ligado ao trabaIho (pelo menos 21 dias) ou ausências repetidas por razões de saúde, o assalariado deve se submeter a um exame efetuado pelo médico do trabalho. O objetivo desse exame é apreciar a aptidão do assalariado a retomar o seu antigo emprego e a necessidade de uma adaptação das condições de trabalho ou de uma readaptação do assalariado.

Ora, a questão é determinar se é desejável aplicar o dispositivo do intervalo terapêutico ao trabalhador que retorna de uma licença por problemas ligados à sua saúde mental. Na prática, parece mais fácil arranjar a organização e as condições de trabalho em função de constrangimentos de ordem física. No entanto, juridicamente nada impede que se proceda a um re-arranjo do ambiente de trabalho em função de problemas de ordem mental. Nenhum texto estabelece que esses ordenamentos destinam-se unicamente ao estado de saúde física do assalariado. Ao contrário, desde a entrada em vigor da lei de modernização social, o empregador dev€ tomar "as medidas necessárias para assegurar a segurança e proteger a saúde física e mental dos trabalhadores do estabelecimento (...)"(3). O artigo L. 241-10-1, $1^{\circ}$, do Código do Trabalho acrescenta que o médico do trabalho está habilitado para propor medidas individuais jus-

(3) Art. Lei n. 230-2 alinéa 1er do Código do Trabalho. 
tificadas por considerações relativas nomeadamente ao estado de saúde físico e mental dos trabalhadores. A idéia do intervalo terapêutico aplicada às pessoas psicologicamente frágeis faz ainda mais sentido, tendo em conta a introdução no Código do Trabalho da noção de saúde mental(4). Desde então, um retorno ao trabalho adaptado ao estado de saúde dos trabalhadores não é reservado, exclusivamente, aos assalariados que voltam depois de afastados por problemas de saúde física, porque o Código do Trabalho reconhece agora o direito à proteção da saúde "física e mental" no trabalho.

Para proteger a saúde mental das pessoas psicologicamente frágeis no trabalho e permitir-lhes responder ao direito constitucional ao trabalho e ao emprego, favorecendo a sua inserção profissional, o intervalo terapêutico é uma alternativa a ser pensada. A idéia é estender seu uso para beneficiar os trabalhadores cuja saúde mental não lhes permite suportar o volume de trabalho em tempo integral. O intervalo terapêutico é assim um dispositivo de acompanhamento do trabalho que se pode apresentar como resposta às dificuldades de inserção das pessoas psicologicamente frágeis (I). Trata-se igualmente de elaborar um dispositivo que compreende direitos novos, adequados ao tratamento da saúde mental no trabalho, dos trabalhadores psicologicamente frágeis, assegurando-Ihes um acompanhamento e um controle (II).

\section{I - FAVORECER A INSERÇÃO PROFISSIONAL DAS PESSOAS PSICOLOGICAMENTE FRÁGEIS}

O intervalo terapêutico é conhecido das pessoas que desejam retornar progressivamente ao trabalho após alteração da sua saúde física; mas, ele é muito pouco utilizado em matéria de saúde mental. Ora, qualquer que seja a origem do problema de saúde, quer seja físico ou mental, cada pessoa tem o direito de se beneficiar desse regime de reintegração no meio laboral. Também, o recurso ao intervalo terapêutico é uma idéia forte para responder ao principio do direito ao trabalho e o emprego em proveito das pessoas psicologicamente frágeis $(A)$. $O$ intervalo terapêutico apresenta-se, com efeito, como uma alavanca para ajudar sua inserção ou reintegração profissional (B).

\section{A - Um direito ao trabalho e o emprego das pessoas psicologicamente frágeis}

O art. 6ำ do Pacto Internacional relativo aos Direitos Econômicos, Sociais e Culturais (PIDESC) de 16 de dezembro de $1966^{(5)}$ - ratificado

(4) Ver a esse respeito LEROUGE, L. La reconnaissance d'un droit à la protection de la santé mentale au travail. Droit Social, Paris, 2005. No prelo.

(5) Disponivel em: <http://www.unhchr.ch/french/html/menu3/b/a_cescr_fr.htm>. 
pela França em 4 de novembro de $1980^{(6)}$ - enuncia o principio de que qualquer pessoa tem o direito de obter a possibilidade de ser autônomo financeiramente graças um trabalho. O principio do intervalo terapêutico oferece a possibilidade de favorecer a inserção ou a reintegração profissional das pessoas psicologicamente frágeis.

Além disso, em direito interno, um dos objetivos da futura lei de modificą̧ão da lei de luta contra a exclusão é facilitar o acesso ao trabaIho. A inserção profissional das pessoas psicologicamente frágeis responde, na prática, ao respeito do principio do direito ao trabalho e ao emprego. Esse principio, de valor constitucional, é consagrado no quinto parágrafo do Preâmbulo da Constituição de 1946 que enuncia que "cada um tem o dever de trabalhar e o direito de obter um emprego". Com efeito, não apenas as pessoas psicologicamente frágeis têm o direito de obter um emprego, mas têm, igualmente, o direito de conservá-lo, em decorrência do direito ao trabalho. Essa afirmação é confirmada pelo Conselho Constitucional, que precisa, em uma decisão de 28 de maio de 1983, que compete ao legislador "legislar de modo a assegurar ao máximo o direito de cada um de obter um emprego, favorecendo o exercicio desse direito ao maior número de interessados"(7), entre os quais são incluidas, naturalmente, as pessoas psicologicamente frágeis.

Os trabalhadores mais expostos a uma degradação do seu estado mental são os que têm uma saúde mental particularmente frágil. As pessoas psicologicamente frágeis conheceram perturbações mentais importantes e estão expostas ao risco de recaida. Trata-se, igualmente, de pessoas que não estão medicamente aptas a assumir a carga de trabalho ${ }^{(8)} \mathrm{e}$ a carga mental(9) de um emprego em tempo integral. A fragilidade do seu estado de saúde necessita mudanças na organização e nas condições de trabalho de modo a proteger sua saúde mental contra as alterações possiveis ligadas ao meio profissional e ao seu emprego. Com respeito a essa tomada de consciência sobre a importância da saúde mental no trabalho e os problemas ligados às pessoas psicologicamente frágeis, a segunda câmara civil do Tribunal de Cassação tornou duas decisões interessantes. A primeira, datada de $1^{\circ}$ de julho de 2003, qualificou de acidente de trabalho uma depressão súbita de um assalariado, ocorrida dois dias depois de uma entrevista de avaliação que significou seu rebaixa-

(6) E pelo Brasil em $\epsilon$ de julho de 1992 (Decreto Legislativo n. 592/92)

(7) Décision n. 83-156, DC de 28 de mai de 1983, http://www.conseil-constitutionnel.fr/decision/ 1983/83156dc.htm.

(8) A noção de carga de trabalho é relativa à interação entre um sujeito e as exigências de um determinado meio.

(9) A carga mental corresponde à quantidade de informações que o sujeito deve tratar em um dado tempo. 
mento $^{(10)}$. A segunda decisão, de 15 de junho de 2004, qualificou de acidente do trabalho as perturbações psicológicas que resultaram de uma agressão à faca de um assalariado de banco(11).

Se alguns vêem no intervalo terapêutico um contrato em tempo parcial em favor da inserção profissional das pessoas psicologicamente frágeis, uma idéia pouco original, é necessário ainda que esse sistema seja aplicado. As dificuldades de organização do trabalho em prol das pessoas que sofrem ou que sofreram perturbações mentais são, certamente, mais importantes que para as patologias de ordem física, mas a igualdade dos direitos à inserção profissional exige que cada um tenha acesso ao emprego. Sob pena de discriminação, psicologicamente frágil ou não, cada pessoa tem o direito de se beneficiar de um trabalho. Podendo os problemas encontrados se originarem do trabalho, é ainda mais injusto que um assalariado seja excluido do emprego e marginalizado em decorrência de problemas de saúde mental, que não o impedem, no entanto, de exercer um trabalho por meio de arranjos específicos. Ao contrário, trata-se de recriar o principio da igualdade, permitindo a cada um, de fato, aceder ao mundo do trabalho ou nele permanecer apesar de um estado de saúde mental frágil.

O intervalo terapêutico apresenta-se como um dispositivo juridico que permite às pessoas vitimas de problemas de saúde retomar e continuar no exercicio de seu emprego em condições compativeis com o seu estado de saúde. A idéia é, assim, evitar que as pessoas psicologicamente frágeis, ou aquelas que assim se tornaram por diversas razões, sejam marginalizadas ou saiam do mercado de trabalho. Trata-se igualmente de facilitar o regresso na empresa. O intervalo terapêutico pode então servir de alavanca para favorecer a inserção profissional das pessoas psicologicamente frágeis.

\section{B - Uma alavanca de inserção profissional das pessoas psicologi- camente frágeis}

Em virtude do principio da execução de boa-fé do contrato de trabaIho, agora consagrado expressamente no Código do Trabalho, no artigo L. 120-4, o empregador deve proporcionar ao trabalhador os meios necessários à execução do trabalho que coloca à sua disposição. Esta obrigação implica nomeadamente a definição de um volume de trabalho conforme às competências profissionais do trabalhador e à sua aptidão física e mental. Os trabalhadores psicologicamente frágeis estão em posição de fraqueza, eles devem ser protegidos e gozar, se for o caso, de um regime juridico de trabalho adaptado ao seu estado de saúde para que possam

(10) Cass. civ. 2ème 1er juillet 2003, RJS, 10/03, n. 1.222.

(11) Cass. civ. 2ème 15 juin 2004, RJS, 8-9/04, n. 965. 
conservar o seu emprego. O dispositivo do intervalo terapêutico retoma 0 principio da "adaptação do trabalho ao homem" contido na diretiva de 12 de junho de $1989^{(12)}$ relativa à aplicação de medidas que visam promover a melhoria da segurança e a saúde dos trabalhadores no trabalho, internalizada pela lei de 31 de dezembro de $1991^{(13)}$. Devido à participação do direito ao trabalho na dignidade do ser humano e ao lugar que o trabalho ocupa na sociedade, a noção de dignidade da pessoa humana exprime-se também através da proteção da saúde mental no trabalho e da conservação de um emprego. O trabalho deve conservar a sua "força estruturante"(14) na vida social da pessoa, ainda mais, poder-se-ia dizer, quando se trata de pessoas com saúde mental frágil.

Um dispositivo adaptado no âmbito do intervalo terapêutico oferece a possibilidade às pessoas psicologicamente frágeis de se beneficiarem de uma organização do trabalho e de um ambiente profissional compativeis com a sua saúde. As condições de trabalho e as tensões profissionais susceptiveis de degradar o seu estado de saúde mental encontrar-se-iam atenuadas. O artigo L. 241-10-1 do Código do Trabalho oferece a oportunidade de integrar a idéia de um tempo parcial adaptado nas "medidas individuais", propostas ao empregador pelo médico do trabalho, justificadas por considerações relativas nomeadamente "ao estado de saúde física e mental dos trabalhadores".

O intervalo terapêutico contém assim condições práticas e jurídicas que podem acolher direitos novos destinados a tornar o trabalho adaptado aos assalariados cuja saúde mental é frágil. O dispositivo deverá necessariamente compreender a garantia de uma organização e condições de trabalho conformes e considerar os arranjos de horários. Deverá, também, instaurar um regime que permite suspensões do contrato de trabatho no caso de problemas ligados à saúde mental do assalariado.

Para se assegurar da correta aplicação do intervalo terapêutico em favor das pessoas psicologicamente frágeis, um regime juridico ad hoc deve ser organizado a fim de assegurar o controle e o acompanhamento do dispositivo.

\section{II - CONTROLAR E SEGUIR INTERVALO TERAPEUUTICO PARA AS PESSOAS PSICOLOGICAMENTE FRÁGEIS}

Em virtude do artigo L. 230-2, $\S 1^{9}$, do Código do Trabalho, o empregador responde por uma obrigação de prevenção para com os seus

(12) Directive n. 89/391/CEE de 12 de junho de 1989 sobre a implementação de medidas visando promover a melhora da segurança e da saúde dos trabalhadores no trabalho, JOCE L. 183 de 29 de junho de 1989, p. 1.

(13) Lei n. 91-1414, de 31 de dezembro de 1991 relativa à proteção dos trabalhadores, JORF de 6 e 7 de janeiro de 1992, p. 319.

(14) COSTER (de) (M.), PICHAULT (F.), Traité de sociologie du travail, De Boeck Université, Coll. Ouvertures sociologiques, $2^{2}$ ed., 1988, p. 63. 
assalariados, devendo tomar "as medidas necessárias para assegurar a segurança e proteger a saúde física e mental dos trabalhadores (...)". Para assegurar a eficácia do intervalo terapêutico em favor das pessoas psicologicamente frágeis, um regime de acompanhamento e de controle deve ser instaurado na empresa e fora dela (A). Além disso, a definição da obrigação de prevenção do empregador estendida à saúde mental desde a lei de modernização social oferece um quadro jurídico adaptado à instauração e à aplicação do intervalo terapêutico em proveito de assalariados psicologicamente frágeis $(B)$.

\section{A - O acompanhamento e o controle do intervalo terapêutico na empresa e fora dela}

Se o legislador não intervém, o juiz deverá deduzir a obrigação de prevenção do empregador em relação aos assalariados psicologicamente frágeis. Com efeito, o trabalho de interpretação do juiz é indispensável na medida em que nenhum texto precisa, atualmente, com exatidão, o regime da prevenção dos riscos ligados à saúde mental na empresa. O juiz terá, também, um papel capital devido à interpretação que fará da obrigação de prevenção do empregador. Uma interpretação extensiva irá no sentido de um alargamento dos riscos que podem provocar uma alteração da saúde mental e da proteção das pessoas psicologicamente frágeis.

Apenas alargar a obrigação de prevenção do empregador não é, contudo, satisfatório, pois ainda será necessário assegurar-lhe um acompanhamento. As instituições da empresa têm, assim, um papel a desempenhar para velar pela boa aplicação das medidas de prevenção decididas pelo empregador no âmbito do intervalo terapêutico.

A lei de modernização social(15) estende a competência do Comitê de Higiene, Segurança e Condições do Trabalho (CHSCT) atribuindo-lhe, especialmente, a missão "de contribuir para a proteção da saúde física e mental"(16) no trabalho. As competências do CHSCT oferecem a possibilidade de analisar os riscos profissionais aos quais podem ser expostas as pessoas psicologicamente frágeis no exercicio das suas funções. O Comitê pode, também, formular um parecer sobre a adequação das condições de trabalho relativas aos assalariados que se beneficiam do intervalo terapêutico. No âmbito da sua missão de vigilância das condições de trabalho, o CHSCT é igualmente competente para proceder a inspeções. O Comitê de Higiene, Segurança e Condições do Trabalho pode, assim, velar pela correta aplicação das disposições relativas à adequação da organização e das condições de trabalho relativas à instauração do intervalo terapêutico. Para um acompanhamento ainda melhor adaptado, o

(15) Lei n. 2.002/73 de modernização de 17 de janeiro de 2002, JORF de 18 de janeiro de 2002, p. 1008.

(16) Art. Lei n. 236-2 alinéa 2 do Código do Trabalho. 
CHSCT pode, usando sua competência, confiar uma missão a um dos seus membros. Tratar-se-ia, nesse caso, de uma missão de acompanhamento dos assalariados psicologicamente frágeis que trabalham no âmbito do intervalo terapêutico.

A outra instituição ligada à proteção da saúde na empresa é o serviço de saúde do trabalhador. Com efeito, o médico do trabalho tem por vocação agir sobre o meio ambiente laboral e promover a adaptação do trabalho ao homem. É, assim, competente para propor ao empregador medidas individuais para tratar a "saúde física e mental" do assalariado(17). O médico do trabalho deve consagrar um terço do seu tempo ao meio ambiente do trabalho. Ele dispõe, assim, da ocasião de verificar as condições de trabalho no terreno e de dar uma atenção especifica aos assalariados psicologicamente frágeis. Além disso, fora da visita periódica que se realiza, pelo menos, a cada 24 meses $^{(18)}$, seria possivel consagrar visitas médicas regulares aos titulares do intervalo terapêutico, cuja saúde mental é reconhecidamente frágil.

Por último, o balanço social produzido pelo Comitê de Empresa pode participar no acompanhamento do dispositivo instaurado na empresa em prol das pessoas psicologicamente frágeis. Com efeito, esse documento serve, em parte, de fundamento para o exercicio das prerrogativas do Comitê de Empresa em matéria de condições de trabalho. Ora, o balanço social apresenta o interesse de se constituir em um meio de informação dos assalariados sobre o estado das condições de trabalho na empresa. Ele pode, assim, ser um instrumento que permite, especialmente, visualizar o acompanhamento da adequação das condições de trabalho destinadas às pessoas psicologicamente frágeis.

Além disso, a questão do acompanhamento induz necessariamente aquela do controle da correta aplicação desses direitos novos na empresa. O papel da inspeção do trabalho será determinante para velar pelo respeito das disposições relativas ao regime dos assalariados psicologicamente frágeis. A ação é conduzida pelos inspetores do trabalho cuja missão deve considerar, desde a entrada em vigor da lei de modernização social, a saúde mental. A organização e as condições de trabalho tendo sido adequadas em função da saúde precária dos assalariados, o controle dos inspetores deverá se realizar, contudo, em ligação com médicosinspetores do trabalho(19). Para além das suas competências em matéria médica, esses médicos-inspetores do trabalho apresentam, igualmente, a vantagem de estar em relação com os Comitês Técnicos das Caixas de

(17) Art. Lei n. 241-10-1 do Código do Trabalho.

(18) O Decreto n. 2.004-760, de 28 de julho de 2004 relativo à reforma da medicina do trabalho e modificando do Código do Trabalho sobre a periodicidade do exame médico de 12 para 24 meses, no minimo, salvo para os assalariados que se beneficiam de um seguimento médico especial.

(19) Art. Lei n. 612-1 do Código do Trabalho. 
Seguridade Social com o objetivo de velar pela proteção da saúde dos trabalhadores ${ }^{(20)}$. Essas competências poderiam contribuir para refinar 0 documento único, de acordo com a progressão das iniciativas dessas instituições no sentido da prevenção dos riscos ligados à saúde mental no trabalho(21).

A missão dos sindicatos é igualmente determinante no controle da correta aplicação na empresa das medidas em prol dos assalariados com saúde mental frágil. Com efeito, nos termos do artigo L. 411-1 do Código do Trabalho, os sindicatos têm por objeto a defesa dos direitos e os interesses materiais e morais tanto coletivos quanto individuais na empresa. Os delegados sindicais possuem, também, entre as suas vocações, a preocupação de intervir em favor dos trabalhadores que sofrem de perturbações mentais ligadas ao trabalho(22). A ação sindical deve ajudar a uma melhor assunção das condições laborais, tendo com novo elemento a saúde mental.

Os delegados do pessoal têm, igualmente, um papel importante a desempenhar no controle da implementação das medidas em prol dos assalariados psicologicamente frágeis. De fato, eles representam o primeiro interlocutor dos trabalhadores, que devem, como uma de suas missões, apresentar ao empregador todas as queixas individuais ou coletivas relativas, particularmente, à aplicação das leis e regulamentos relacionados à higiene e à segurança. Eles são competentes para representar à inspeção do trabalho as queixas e as observações relativas "à aplicação das prescrições legislativas e regulamentares das quais é encarregada de assegurar o controle"(23). É possivel, então, que um delegado do pessoal represente à inspeção do trabalho com o objetivo de fazer aplicar disposições em prol de assalariados cujo estado de saúde mental necessite um regime de trabalho específico na empresa. Além disso, em virtude do artigo L. 422-1-1 do Código do Trabalho, o delegado do pessoal, que constata um atentado à saúde mental, pode representar ao empregador, que deve diligenciar imediatamente um inquérito para remediar a situação. Se nenhuma solução for encontrada e se o assalariado não se opuser por escrito, o delegado do pessoal pode representar à sessão de julgamento do Conseil des Prud'hommes, que delibera em recurso provisório. O juiz poder ordenar medida destinada a fazer cessar o atentado à saúde mental do assalariado, ou seja, medidas próprias a ajustar a condição de trabalho ao perfil do assalariado frágil. 0 juiz pode, também, acompanhar sua decisão de uma obrigação(24). Contudo, outras sanções são possiveis.

(20) Art. Decreto n. 612-1 do Código do Trabalho.

(21) Ver a esse respeito LEROUGE (L.), op. cit.

(22) Relatório do Conselho Econômico e Social de 11 de abril de 2001 sobre o assédio moral no trabalho, Éditions des JO, p. 72.

(23) Art. Lei n. 422-1 do Código do Trabalho.

(24) Art. Lei n. 422-1-1 alinéa 4 do Código do Trabalho. 
Como evocar o controle da aplicação desses novos direitos em favor dos trabalhadores psicologicamente frágeis sem abordar as sanções ligadas à incorreta aplicação dessas disposições? Em último caso, os processos instaurados na seqüência de um boletim de ocorrência elaborado pelo inspetor do trabalho podem levar a sanções penais. Esse procedimento, no entanto, demanda tempo e não é necessariamente o mais dissuasivo e o mais eficaz. O problema levanta, também, a questão sobre quais sanções são melhor adaptadas para regularizar a situação em prol do assalariado frágil.

Uma primeira sanção leve e preventiva de uma sanção mais pesada seria de ordem procedimental. Com base em um termo de ajustamento de conduta, a idéia seria atribuir um prazo razoável para dar o tempo ao empregador de atualizar o documento único antes que uma sanção the seja aplicável. Se o empregador não responder nos prazos fixados, ele se exporia às sanções clássicas de ordem penal, mas, também, porque não, de ordem fiscal. Com efeito, as sanções estritamente penais parecem ser menos temidas que as medidas que penalizam a empresa pelo jogo de uma sobretaxação, desde que manipulado com precaução(25).

\section{B - A compatibilidade da obrigação de prevenção do empregador e o intervalo terapêutico}

Inevitavelmente coloca-se a questão de determinar se os direitos relativos ao intervalo terapêutico fazem parte da obrigação geral de prevenção do empregador. O empregador deve, de fato, prevenir os riscos inerentes ao trabalho e proteger a saúde fisica e mental dos seus assalariados $^{(26)}$. Deve igualmente velar pela "adaptação destas medidas para que tenha em conta a mudança das circunstâncias e tendam para a meIhoria das situações existentes"(27). Que o risco de alteração do estado de saúde mental seja grande ou pequeno, seria necessário esperar que seja acordado ao trabalhador psicologicamente frágil o afastamento por doença para que empregador tomar as medidas adequadas? A resposta à questão precedente é, evidentemente, negativa. O empregador deve, com efeito, se encarregar de tomar as disposições necessárias de modo a prevenir a realização desse risco. Assim, a prevenção dos riscos de alteração da saúde mental no trabalho das pessoas psicologicamente frágeis inscrevese inegavelmente na perspectiva da obrigação de prevenção do empregador enunciada no artigo L. 230-2 do Código do Trabalho, mas responde, também, ao princípio da adaptação do trabalho ao homem ${ }^{(28)}$. Essa obri-

(25) TEYSSIÉ, B. Sur le droit pénal du travail. Droit Social, Paris, p. 941, nov.2000.

(26) Art. Lei n. 230-2 alinéa 1er do Código do Trabalho.

(27) Ibidem.

(28) Ibidem. II.d. 
gação pode, igualmente, ser deduzida para os trabalhadores cuja fragilidade psicológica é conhecida tanto quanto para os assalariados em boa saúde, mas cujo estado mental pode sofrer pelas condições de trabalho ou se fragilizar em conseqüência de um choque emocional(29).

O futuro da saúde mental no trabalho reencontra-se, por conseguinte, na inscrição desses novos direitos na obrigação geral de prevenção do empregador ${ }^{(30)}$. $O$ intervalo terapêutico é um dispositivo jurídico que se inscreve inegavelmente nesta perspectiva.

A obrigação de segurança e prevenção do empregador remete direito de aposentadoria do trabalhador. De fato, o assalariado que tem um motivo razoável para pensar que uma situação de trabalho apresenta um perigo grave e iminente para a sua vida ou a sua saúde deve assinalá-lo imediatamente ao empregador. Este último não pode obrigar o assalariado a retomar a sua atividade enquanto a situação persistir(31). Ora, a questão que agora decorre do direito de aposentadoria é como aplicá-lo à saúde mental, especialmente, para os trabalhadores psicologicamente frágeis.

Com efeito, certas situações de trabalho podem apresentar um perigo grave e iminente para a saúde mental da pessoa? Se o caráter de gravidade é qualificável, o critério de iminência do perigo é, pelo menos, de mais difícil qualificação em matéria de saúde mental. A depressão brus$\mathrm{ca}^{(32)}$ bem como o suicídio(33), contudo, são exemplos que mostram quanto a degradação da saúde mental pode se revelar extremamente rápida e ser qualificada de acidente do trabalho, particularmente quando se refere a pessoas psicologicamente frágeis. Estas poderiam, assim, invocar o seu direito à aposentadoria porque suas condições de trabalho são de molde a prejudicar a sua saúde mental, considerando-se sua fragilidade psicológica. O futuro da saúde mental no trabalho e as pessoas psicologicamente frágeis passa, portanto, também, pela extensão do direito à aposentadoria por saúde mental, ou seja pelo reconhecimento de situações que podem provocar uma alteração grave da saúde mental.

(29) Cf. Civ. $2^{\text {ème }} 1^{9}$ de julho de 2003 e 15 de junho de 2004. Op. cit.

(30) LEROUGE, L. Op. cit.

(31) Art. Lei n. 231-8 do Código do Trabalho.

(32) Cass. civ. $2^{\text {eme }} 1$ er juillet 2003, RJS, 10/03, n. 1.222, depressão súbita de um assalariado, ocorrida dois dias após uma entrevista de avaliação que resultou em seu rebaixamento, qualificada como acidente de trabalho; Cass. civ. $2^{\text {ème }}$ de 15 de junho de 2004, RJS, 8-9/04, n. 965.

(33) Cass. soc. 20 avril 1988, Bull. civ., 1988, n. 241, suicidio realizado em um momento de desespero após advertência do empregador, qualificada de acidente do trabalho. 